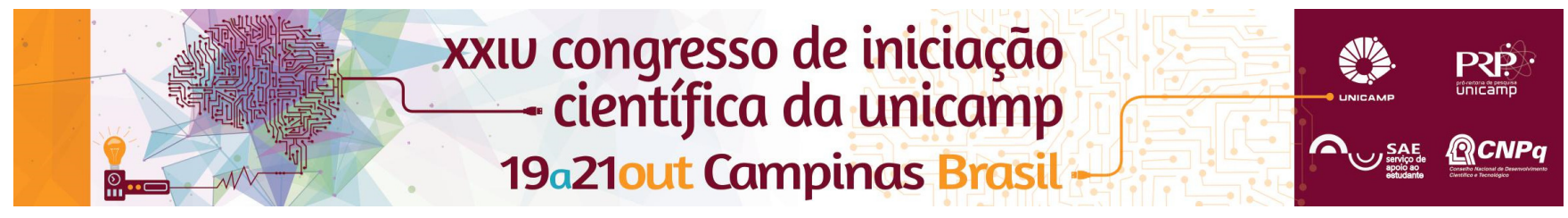

\title{
Evaluation of antioxidant capacity stability of jamun pulp powder (Syzygium cumini L.) submitted to spray drying process
}

\author{
Vitor G. da Silva*, Luiz G. P. Martin, Rosa H. Aguiar, Rafael A. de Oliveira.
}

\begin{abstract}
Jamun (Syzygium cumini L.) is a species from Indonesia, China and the Antilles, however cultivated in many countries. Its fruits are mainly consumed in natura, but also processed into jams, jellies, liqueurs, wine and other derivatives. Jamun has high content of vitamins $\mathrm{C}$ and $\mathrm{E}$, anthocyanins and polyphenols, which present high antioxidant activity and give it potential effect against several degenerative diseases and might represent a nutrition source. This research work aimed to determine the kinetics of degradation of anthocyanins and antioxidant activity of jamun pulp microencapsulated powder, produced from the optimal operational variables established previously, during the storage under different conditions of air temperature and relative humidity. The jamun pulp powder was obtained by spray drying process using Dextrina Snow Flake ${ }^{\circledR}$ E6131 (Corn Products, Mogi-Guaçu, Brazil) as encapsulant agent (concentration 11.5\% (w/w)) and was stored for two months in four different environments combining two air temperatures $\left(25^{\circ} \mathrm{C}\right.$ and $\left.35^{\circ} \mathrm{C}\right)$ and two relative humidities $(22 \%$ and $43 \%)$. The fresh jamun pulp was submitted to centesimal and physical-chemical characterization providing similar results to literature. For the final results, the analysis of shelf life aims to find the best conditions for retention of anthocyanins and antioxidant activity.
\end{abstract}

Key words:

Antioxidant activity, anthocyanins, storage.

\section{Introduction}

Jamun is a berry-shaped fruit, with a single seed, surrounded by a thick and edible, mucilaginous, sugary and astringent pulp. It presents high antioxidant capacity because of high content of vitamins $C$ and $E$, anthocyanins and polyphenols, which features potential effect against several degenerative diseases and might represent a nutrition source.

Spray drying process with microencapsulation gives better conditions for conservation, providing protection against the humidity adsorption and other adverse conditions.

Therefore, this research work aimed to determine the content of anthocyanins and the antioxidant activity of the powder during the storage under different temperatures and relative humidities of air, and to find the best conditions for the retention of anthocyanins and antioxidant activity.

\section{Results and Discussion}

Jamun pulp was characterized for centesimal and physical-chemical composition, presenting the following results: moisture content - $92.8 \%$; total soluble solids $9.0^{\circ}$ Brix at $20^{\circ} \mathrm{C} ; \mathrm{pH}-3.95$; total titratable acidity -5.31 $\%$ of citric acid; ash content $-3.16 \%$; lipids content -0.3 $\%$; carbohydrates content $-3.04 \%$; protein content -0.7 $\%)$; color $-45.1(\Delta \mathrm{E})$.

The drying process was done using Dextrin Snow Flake as encapsulant agent in concentration of $11.5 \%(\mathrm{w} / \mathrm{w})$ and adopting inlet temperature of $168^{\circ} \mathrm{C}$. The drying process was developed in a laboratory spray dryer (Model B191, BÜCHI, Flawil, Switzerland). The obtained drying yield was $50.4 \%$ and the final powder presented moisture content of $1.6 \%$.

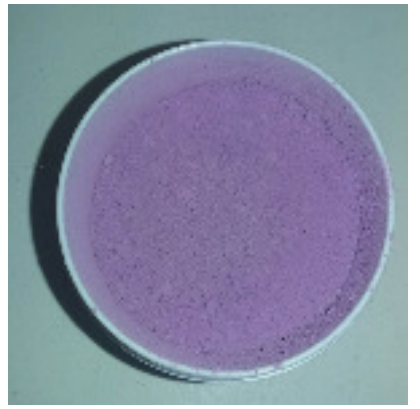

Figure 1. Jamun pulp microencapsulated powder.

The determination of antioxidant capacity and the content of anthocyanins of the pulp and the powder and its physical-chemical characterization will be carried, as well as storage and shelf life analysis, evaluating fortnightly content of anthocyanins, the antioxidant activity, hygroscopicity and moisture content. After 60 days of storage, it was expected to determine the kinetic curve for degradation, finding the best conditions for retention of anthocyanins and antioxidant activity of the powder.

\section{Conclusions}

The pulp characterization presented similar results of literature and the conditions of optimal operational parameters presented satisfactory results in spray drying process.

\section{Acknowledgement}
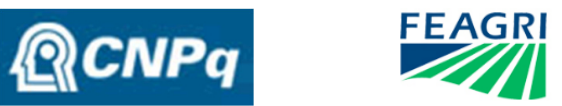

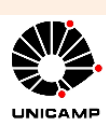

